\title{
Familias transnacionales desde el sur. Testimonios de la globalización en Chile. Javiera Cienfuegos Illanes (coord.). Ediciones Universidad Academia de Humanismo Cristiano
}

\author{
RESEÑADO POR \\ JULIÁN VEJAR ${ }^{1}$ \\ https://orcid.org/0000-0003-2726-8552
}

La globalización no es un fenómeno nuevo en el estudio de las ciencias sociales. Sin embargo, la aceleración de la sociedad, los cambios geopolíticos, las transformaciones culturales y las prácticas de movilidad y cambios en la compresión del espacio-tiempo, van ajustando y redefiniendo los contornos y los límites de lo que hemos definido por globalización. Las fronteras se redibujan y nos muestran, a través de situaciones como la pandemia que nos amenaza hoy, su fragilidad y las conexiones que han dado forma a una red asimétrica de hilos y vínculos a través del mundo.

En este proceso de mutación y transgresión de las fronteras, las formas de vida en sociedad son las que alcanzan una nueva morfología, y en ella, es donde se insertan los trabajos presentados en este libro. Las experiencias y sujetos/as en migración son parte del nuevo paisaje, cuerpo y sentido de las sociedades contemporáneas. La sociedad chilena muestra en su radiografía una riqueza cultural que va dinamizando las comprensiones de lo cotidiano, la identidad y la vida en colectivo, lo cual es reforzado en los testimonios que componen cada capítulo de este libro.

1. Sociólogo. Dr. en Sociología por la Friedrich Schiller Universität de Jena (Alemania). Investigador del Instituto de Historia y Ciencias Sociales. Universidad Austral de Chile (Valdivia, Chile). Investigador adjunto de Society, Work \& Politics Institute (SWOP) de la Universidad Wittwatersrand (Johannesburgo, Sudáfrica). Investigador Principal Fondecyt No. 1200990. Sus líneas de investigación giran en torno a los estudios del trabajo, interseccionalidad y relaciones laborales; Territorio, extractivismo y cultura; precariedad y sociología pública en el Sur Global. Correo electrónico: dasten.julian@uach.cl. 
"Familias transnacionales desde el sur", nos ofrece una mirada a esos espacios privados que son la construcción de lo afectivo, las emociones, el dolor y las prácticas de tensión que componen los tejidos e hilos que se encuentran en los tránsitos, idas y venidas de un mundo móvil y plástico como lo es la migración y la conformación de las familias, entornos y redes transnacionales. En este libro Javiera Cienfuegos Illanes, su coordinadora, nos lleva a un crisol de rostros, voces, configuraciones, tecnologías y territorios, que exhiben fibras sensibles de las biografías más humanas y demasiado humanas que componen los sueños, dolores y violencias que movilizan a las personas a migrar, y a inventarse, recrearse y habitar de manera deslocalizada en el sur global.

El libro arranca con el capítulo de Ligia Gallardo Faúndez, titulado "la provinciana", mostrándonos los caminos recorridos en las migraciones internas en un país centralizado y estigmatizador. En una cálida narrativa literaria la autora nos acerca en una reflexiva proximidad a empaparnos del libro en su conjunto. En el siguiente capítulo, María Victoria Galleguillos “Las fotografías de Leyre” nos sumergen a través de imágenes y una trayectoria de migración que es un proceso de transición en la búsqueda de sentido. La autora destaca las transferencias culturales como un tejido que sujeta y da vida al movimiento del significado y los cuerpos migrantes.

A continuación, tenemos dos capítulos que se centran en la relación de maternidad y las trayectorias migratorias. Primero, encontramos el capítulo de Catherine Ortega Yanca titulado "Alicia y el rol sacrificial de la mujer que migra". En él nos muestra el rostro de Alicia, quien, a través de su historia de vida, nos introduce en laberintos y fronteras que nos transportan a seguir una línea invisible que comunica Florida (EEUU) con el centro de Santiago. A continuación, Javiera Cienfuegos nos presenta "Sobre madres migrantes y hogares escindidos", en donde conocemos la maternidad tensionada y desafiada de mujeres peruanas que han migrado a Santiago de Chile. Javiera nos coloca en una posición de escucha, situándonos en el medio de una red de reciprocidades que no tiene un lugar fijo, en donde el sufrimiento, el regocijo y el sacrificio se mezclan para dar vida a prácticas de maternidad y familias diversas.

En el siguiente capítulo Consuelo Guerrero Lacoste nos plantea una interesante experiencia y temática en "Los duelos del migrante, las nuevas tecnologías y las alteraciones en las prácticas de la familia transnacional”. En este capítulo Consuelo nos introduce al sentido de pérdida, sufrimiento y temor que involucra la migración, y las formas que cobra en los sujetos a través del duelo. Nos lleva a problematizar el duelo como una experiencia que afecta a las familias, su componente transgeneracional y los elementos psicológicos y sociales que se entrecruzan. A través de un juego de espejos en el relato, el cual reúne imaginariamente a madre y a hijo, la autora nos muestra el ejercicio de dispositivos tecnológicos como re-configuradores y modeladores de las prácticas de familias transnacionales. 
En el siguiente capítulo, Annika Hermann introduce en nuestras cabezas el concepto de una "familia postgeográfica". La autora nos trae la voz de Michael, quien en su ir y venir por el flujo empresarial, nos conecta con la genealogía, funcionamiento y redefiniciones de una familia transnacional. Su familia aparece como un campo problemático entre Chile y Alemania, en un contexto donde se vuelven cada vez más una regularidad la existencia de familias transnacionales. Esta historia nos transporta a negociaciones, tensiones, viajes, emociones y energías que vuelven la idea de una postgeografía de lo familiar una pregunta por el presente y el futuro de las migraciones.

El capítulo de Carolina Ossandón Llompart se titula "La colombiana", y es un capítulo que nos trae la historia de una migrante colombiana contada en sus propias palabras y sin ninguna otra mediación que el lenguaje escrito. La voz de "la colombiana" nos muestra una intersección de situaciones de violencia patriarcal que van dibujando los contornos del presidio femenino y de una maternidad escindida. Desde la familia, la explotación sexual, la humillación, el tráfico de drogas, la cárcel y la religión, esta historia, nos expresa diversas precariedades, encierro, pérdidas e intentos de reparación de fisuras de un deseo nunca cumplido.

"La relación intercultural de la familia multisituada venezolana", es el capítulo presentado por Edward Sultant y Andrea Freites, en el que brevemente se expone, a través de la voz de la autora venezolana, como el desplazamiento, la tecnología, la búsqueda y la interculturalidad, nos invitan a pensar en una multi-localización de la familia. Este capítulo es presentado en español y en creolé, abriéndonos la cárcel lingüística en que experimentamos la realidad y la migración como un pathos bidireccional y cerrado. A través de un relato directo y claro, Andrea nos permite ingresar a lo íntimo de sus pasos, los trazos que dibuja para sostener la comunicación con su familia y el desafío de enfrentarse a una nueva cultura, con sus propias prácticas y costumbres. La reflexión que cierra el capítulo parece ser una ventana a través de la cual la misma sociedad chilena está llamada a observarse para entender la multiplicidad de familias que hoy coexisten y conviven en Chile.

A continuación, Leonora Beniscelli, Caru Garzón y Cris Amariles, nos presentan el capítulo "Caro y Cris: dos colombianas 'emancipadas' en el cono sur”, los cuales nos muestran dos biografías entroncadas y atadas por el pasado, el presente y el futuro. Haciendo una revisión de sus vidas, Caru y Cris, nos cuentan sus trayectorias migratorias, marcadas por los estudios y la ruptura de los cánones tradicionales de sus familias. Ambas se mueven entre la distancia, la autonomía, el cuidado y el acompañamiento, y nos interrogan por las rupturas, proximidades y redes que la migración produce entre familias, entornos y personas. La riqueza de este capítulo está en las múltiples fugas y encuentros que se producen en una vida en tránsito y viaje, pero se ancla en la figura materna como un componente deslocalizador de la identidad. 
En "La rumba no es como ayer", Rosario Medina y Vanessa Laverde nos traen en su conversación un intercambio intercultural en que se reconocen desde la amistad y la reciprocidad. Vanessa nos da paseo por su vida, su viaje a Chile, sus amores y separaciones, mientras Rosario va empapándonos de la intertextualidad del diálogo, el espacio y los olores. En el relato afloran los problemas, las distancias y el encuentro con Colombia, en una dinámica de conversación que nos aproxima y nos hace muy vivida toda la historia. La chilombianidad, como lugar identitario, entre lo uno y lo otro, nos invita a pensar entre sonrisas la hibridez de lo nuestro y lo tuyo para vivir lo transnacional.

En una experiencia de conectividad y sincronicidad en la distancia, "Habemus guaguam" de Gabriela Valero Cañas y Elena Vicario, nos introducen a la intimidad del proceso de embarazo y de parto enfocándonos en la relación de distancia geográfica con su familia en México. En este capítulo podremos ver como un tipo de relación con la tecnología introduce un componente virtual en la compresión del tiempo y el espacio, permitiendo construir lugares, interacciones, recuerdos y emociones que van forjando una cultura de comunicaciones en la presencia y ausencias.

Muy relacionado con el capítulo anterior, "Los arreglos de cuidado en el 'chat familiar': una práctica de la familia transnacional”, presentado por Gisela Valenzuela González, nos muestra un ejemplo de cómo el desafío de la ausencia física es enfrentado por dos hermanas colombianas en Chile. En su intento de dar continuidad a los vínculos afectivos, y potenciar una participación, negociación y distribución de los cuidados de familiares enfermas (madre y hermana mayor) en Colombia, nuevamente los soportes tecnológicos crean espacios virtuales de proximidad y de cercanía.

"Relatos de una colombiana en Chile", es un capítulo presentado por Carla Gatica Garay, en él que Laura, la protagonista de esta historia, nos cuenta parte de su vida y de sus migraciones. Laura nos muestra como en múltiples movilidades los procesos y motivos de migración poseen un carácter multifactorial. En estos procesos Laura modela y cambia sus propios intereses, nos adentra en sociedades de destino, donde el prejuicio, los estereotipos y el estigma se entrecruzan con las autopercepciones, procesos de búsqueda personal y la conservación de los lazos emocionales del lugar de origen. Laura es el trazado de un hilo que se entreteje entre Bogotá, EEUU, Cataluña y Santiago.

En el epílogo del libro, Javiera Cienfuegos, en un movimiento muy sutil y bello, nos abre su propia intimidad en "la familia transnacional como acto romántico y político". Sin descuidarse en ningún momento, y con cierta lucidez de los privilegios que acompañan su movilidad, la autora nos entrega un manifiesto poético de su propia experiencia en la movilidad y la conformación de una familia transnacional. En este capítulo se conjugan experiencias, reflexiones teóricas y emociones prácticas de la autora, con lo cual asistimos a un cierre del libro que sitúa el esfuerzo intelectual, político y ético que acompaña a la obra: el cultivo de los abrazos infinitos. 
De conjunto, el libro sucede en un telón de fondo donde las mujeres son las principales protagonistas. A excepción de Michael, las biografías y voces que cuentan estas historias transnacionales son mujeres. Aquí encontramos las referencias Lagarde (1990), con este cautiverio que no tiene lugar fijo, ni tampoco tiempo. Allí donde parece haber unidad y encuentro, la familia, por ejemplo, también se dibujan las tensiones, conflictos y el poder. Estas historias post-geográficas nos invitan a pensar en los testimonios y estas vivencias como parte de una trama y un andamiaje de relaciones que exceden lo nacional, lo masculino y la blanquitud en la conformación de una idea de globalización con rostros, cuerpos y vidas.

\section{Referencia}

Lagarde, Marcela (1990). Cautiverios de las mujeres: madresposas, monjas, putas, presas y locas. Ciudad de México: Universidad Nacional Autónoma de México. 


\title{
CUHSO
}

Fundada en 1984, la revista CUHSO es una de las publicaciones periódicas más antiguas en ciencias sociales y humanidades del sur de Chile. Con una periodicidad semestral, recibe todo el año trabajos inéditos de las distintas disciplinas de las ciencias sociales y las humanidades especializadas en el estudio y comprensión de la diversidad sociocultural, especialmente de las sociedades latinoamericanas y sus tensiones producto de la herencia colonial, la modernidad y la globalización. En este sentido, la revista valora tanto el rigor como la pluralidad teórica, epistemológica y metodológica de los trabajos.

\author{
EDITOR \\ Matthias Gloël \\ COORDINADORA EDITORIAL \\ Claudia Campos Letelier \\ CORRECTOR DE ESTILO Y DISEÑADOR \\ Ediciones Silsag \\ TRADUCTOR, CORRECTOR LENGUA INGLESA \\ Aurora Sambolin Santiago \\ SITIO WEB \\ cuhso.uct.cl \\ E-MAIL \\ cuhso@uct.cl \\ LICENCIA DE ESTE ARTÍCULO \\ Creative Commons Atribución Compartir Igual 4.0 Internacional
}

